\title{
A Modified Fiber-Reinforced Plastics Concrete Interface Bond-Slip Law for Shear-Strengthened RC Elements Under Cyclic Loading
}

\author{
Efe Selman, ${ }^{1}$ Ninel Alver ${ }^{2}$ \\ ${ }^{1}$ Department of Civil Engineering, Izmir Institute of Technology, Izmir, Turkey \\ ${ }^{2}$ Department of Civil Engineering, Ege University, Izmir, Turkey
}

\begin{abstract}
The objective of this article is to realistically analyze fiber-reinforced plastics (FRP) retrofitted reinforced concrete structures under cyclic loading taking into account FRP-concrete bond-slip law with cyclic bond degradation. In literature, even though numerous studies have been conducted in FRP-concrete interface bond-slip modeling under cyclic loads, a small number of them consider the influence of cyclic degradation on FRP-concrete interface bond behavior. Within this framework, the bond-slip law for carbon fiberreinforced plastics-concrete interface is revised by utilizing Harajli's and Ko-Sato's approaches. The procedure is distinct from others because it develops existing deficiencies of these approaches, whereas a more reliable modeling process is proposed for use in practice. Conventional bond-slip law of Lu et al. is compared with this interface relationship stated in this investigation and the difference is clearly shown in terms of structural parameters. Experimental tests are conducted at the same time for verification. It is proved that cyclic bond degradation affects the interface behavior; thus, the structural response cannot be omitted in structural evaluations. Structural performance measures are obtained in good agreement for each level of cycles. The technique proposed clearly exhibits structural response difference between monotonic and cyclic loadings while good agreement is reached with experimental results. POLYM. COMPOS., 37:3373-3383, 2016. (C) 2015 Society of Plastics Engineers
\end{abstract}

\section{INTRODUCTION}

Proper and effective structural performance assessment of fiber-reinforced plastics (FRP) strengthened reinforced concrete (RC) structures has long been an important goal of researchers and engineers. Numerous design and

Correspondence to: E. Selman; e-mail: mefeselman@gmail.com Contract grant sponsor: TUBITAK (The Scientific and Technological Research Council of Turkey); contract grant number: 111M559. DOI 10.1002/pc.23535

Published online in Wiley Online Library (wileyonlinelibrary.com).

(C) 2015 Society of Plastics Engineers assessment techniques are generated and developed in both experimental and analytical framework in order to achieve better evaluations. At this point, the structural FRP debonding mechanism parameters have to be extensively examined and structural mechanism is accordingly determined. In externally bonded FRP systems, bond behavior of the interface between FRP and concrete plays an important role in the performance of FRP-strengthened RC structures. For this reason, bond behavior should be well understood and consequently modeled more realistically in analytical studies in order to make efficient assessments.

Extensive research has been conducted on carbon fiber-reinforced plastics (CFRP)-concrete bond-slip behavior of specimens and the simplest ones are linear or bilinear models [1, 2]. Apart from this, there are some quadratic and exponential models developed [3, 4] and they reflect the reality better than linear models. Theoretical researches are enforced with experimental results and new bond-slip relationships are extracted for CFRP debonding from concrete. Existing studies show that the bond-slip behavior should have two branches such as ascending and descending parts [5] and the characteristics of these portions have to be determined according to some crucial parameters such as concrete strength, FRP plate stiffness, and so on. Linear definitions are made for each ascending and descending parts [1, 2, 6, 7]. A study by $\mathrm{Lu}$ et al. [6] pulled out experimental test results and proposed three new bond-slip models for CFRP-concrete interface. Lu et al., Wu et al., Chen, and Pan [3, 4, 8, 9] derived indirect analytical solutions using numerical simulations. Existing linear and bilinear models are evaluated with finite element (FE) simulations and results are compared with experimental tests. These conventional models mentioned follow a modeling concept, in which the exact solutions of interface differential equations are taken into account instead of linear bond stress-strain relationships simplified. The closed analytical interface solutions are examined for softening and debonding stages [10-13]. 
They are adapted into bond-slip law and debonding mechanism is modified. The analytical solutions coincide successfully with the experimental ones. Attempts to develop realistic analytical models for representing bond-slip behavior have been reported so far including the exact interface differential solution and current models are improved with hardening and softening laws. It is also emphasized that finite element method (FEM) is undoubtedly proved to be a useful tool capable of providing reasonable accurate evaluations of structural behavior in analytical studies [13-20]. However, it is worth noting that these bond-slip models do not include cyclic bond degradation although the specimens are subjected to cyclic loading conditions. Many studies have been conducted with monotonic loading assumption and consequently loading mechanism cannot be reflected realistically. As being aware of this deficiency, this article presents an improved bond-slip model which is based on the combination of Harajli [21] and Ko and Sato's [22] models and this enables a rational evaluation of strengthened RC structures under cyclic loading. The analytical results obtained are compared with experimental identical ones in order to demonstrate the efficiency and accuracy of the bond-slip model proposed.

As stated above, first aim of this study is to modify a bond-slip law for CFRP-concrete interface which considers cyclic bond degradation adequately and second is to demonstrate precisely the structural response difference between CFRP-concrete interface bond-slip relationships under monotonic and cyclic loading.

\section{LOCAL BOND STRESS-SLIP RELATIONSHIP FOR FRP TO CONCRETE INTERFACE}

\section{Theoretical Background}

Even though numerous studies have been conducted in FRP-concrete interface bond-slip modeling under cyclic loads, a small number of them are concerned with $\mathrm{RC}$ members under cyclic loading. Cyclic bond degradation is not much considered so far and bond-slip interface relationships are constructed through monotonic response behavior. Comparisons are made between experimental study under cyclic loading and analytical investigation based on monotonic loading. As have been known, cyclic load mechanism has one of the deterioration processes of great importance for RC structures and consequently cyclic interface bond degradation cannot be omitted in investigations. At this point, Harajli's study [21] has great significance over bond-slip models since it defines cyclic bond degrading response in a detailed way. The developed model accounts for cyclic bond degradation incorporating several important parameters such as cycle numbers, max slip values, and so on. With bond degradation ratios formed, bond-slip curves are updated. Since the compression is too small, it is assumed that first loading in compression occur along the monotonic envelope curve and in next cycles, unloading slope occurs along a line that joins the zero slip point to max negative slip value. Next adequate investigation in this area is belonging to Ko and Sato's work [22]. This investigation develops effective formulations for local interface bond relationship having cyclic bond degradation. It is so an effective approach that cyclic bond degradation can be reflected to bond behavior in both negative and positive directions. With empirical constants proposed $C_{\mathrm{n}}$, shear stiffness of interface is updated and results agreed well with their experimental ones. The stiffness reduction and consequently max slip and bond ultimate stress increase were examined when compared with monotonic loading conditions. In this study, formulations recently proposed for CFRP-concrete bond slip in Harajli's model [21] was further revised with Ko and Sato's [22] approaches and effective interface relationship was proposed under cyclic loading. Experimental work was conducted in order to verify and evaluate theoretical results. Apart from CFRPconcrete bond-slip law proposed, analytical solution was also performed with bond-slip law of conventional approach of Lu et al.'s study [4]. Results obtained from these three works were compared for proving the accuracy of bond-slip interface law proposed in this study. Moreover, structural behavior of CFRP strengthened RC joint was evaluated under cyclic loading conditions considering bond-slip law of CFRP-concrete and steel concrete bond. Load capacity and strain values were discussed for each cycle at interfaces and sections.

\section{Analytical Study}

Figure 1 shows the typical FRP to concrete interface. If the interface mechanism would be briefly examined, increased $P$ external loading is accompanied by increased interfacial shear stresses linearly with the slip between FRP plate and concrete. When the shear strength of concrete is reached, interfacial softening occurs and consequently, shear stress decrease is seen [23]. For this case, softening law is reflected by exponential function of slip values. With the additional slip and load, maximum shear stress of interface is obtained at the loaded end and the ultimate bond capacity is reached. According to this mechanism, many investigations are conducted and several bond-slip laws are proposed in the literature such as bi- or trilinear [1, 2, 6, 7], quadratic [24, 25], and shear exponential models [3, 4, 8, 9]. But, most of these studies show that shear exponential model is more realistic when comparing with their identical experimental works [3, 4]. In this framework, this exponential bond-slip relationship can be generally expressed as (1) and (2) for FRP to concrete interface. In (1) and (2), $k$ represents the slope of bond-slip curve in elastic stage while $\tau$ is the interface shear stress and $\delta$ is the relative displacement between FRP plate and concrete. $\delta_{0}$ is the shear slip corresponding to initial debonding and $\tau_{\max }$ shows the interfacial shear strength. $\beta$ is an index of interfacial softening and can be 


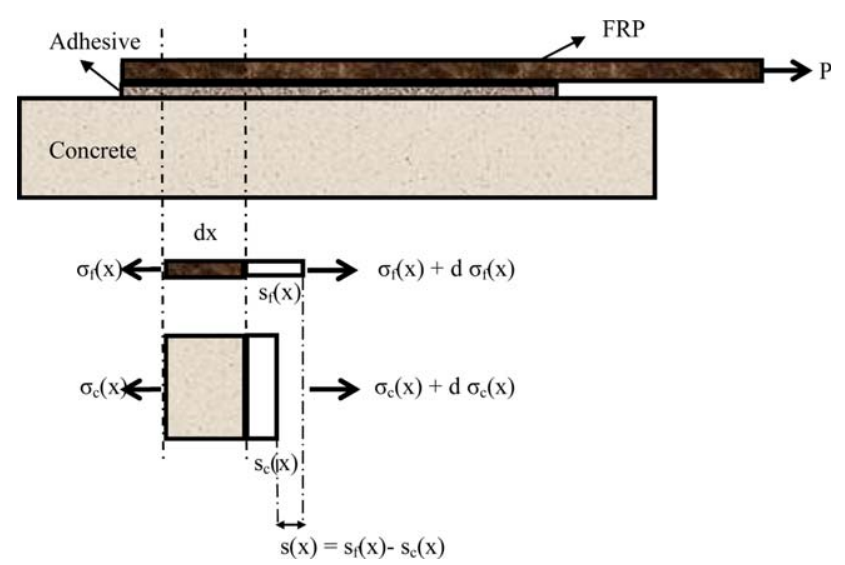

FIG. 1. Analytical model of FRP to concrete interface. [Color figure can be viewed at wileyonlinelibrary.com]

calculated from $G_{\mathrm{f}}$, interfacial fracture energy and $\tau_{\max }$ interfacial shear strength.

$$
\begin{gathered}
\tau=k . \delta ; 0 \leq \delta \leq \delta_{0} \\
\tau=\tau_{\max } \cdot \mathrm{e}^{-\beta(\delta-\delta 0)} ; \delta \geq \delta_{0} \\
\beta=\tau_{\max } / G_{\mathrm{f}}
\end{gathered}
$$

Most of the analytical studies on bond properties are done in monotonic loading conditions although cyclic load is applied in their experimental procedure. It should be underlined that sustained repeating load produce degradation of bond strength and bond stiffness. This can be observed as a slip increment and interface shear strength decrease [26]. Load history has a significant effect on slip. A periodical increase of the maximum value of cyclic force leads to higher peak slip values and consequently the bond stress begins to drop slowly. Shortly, cycling a specimen at different increasing values of slip has a cumulative effect on the deterioration of bond stiffness [26].

In this study, bond-slip relationship is considered under cyclic loading as stated above and Harajli's model [21] is taken into account in modeling cyclic bond-slip relationship of FRP-concrete interface. This approach is selected since this is the only method which cyclic degradation response can be characterized in terms of interface behavior such as interface maximum slip. Its validity and accuracy are demonstrated by Harajli's study [21].

In Harajli's model [21], bond degradation associated with cyclic loading is simulated as bond degradation ratios $\left(u_{\mathrm{n}} / u_{0}\right) ; u_{0}$ is the bond stress at max slip on the envelope curve from first unloading and $u_{\mathrm{n}}$ is the bond stress at max slip which corresponds to tension reloading cycles. This ratio is adequately related with number of cycles and max slip during load history through regression analysis of experimental data and bond-slip relationship is updated with a bond stress reduction versus corresponding larger slip values. Since slip values in compression are negligibly small, it is assumed that the first loading of compression occurs along the monotonic envelope curve in compression [21]. The bond degradation ratio is used for representing both cycle and in cycle strength degradations. Those are easily calculated by ABAQUS program v10 [27]. For example, in first cycle, whereas $u_{\mathrm{n}}$ is computed as $1.214 \mathrm{MPa}$ in ABAQUS program v10 [27] for CFRP no: $5, u_{0}$ is $1.053 \mathrm{MPa}$. The bond degradation ratio is obtained as $1.153(=1.214 / 1.053)$ for the forward portion of the first cycle. Next, this ratio is taken into account as frictional contact property for first cycle in ABAQUS program v10 [27]. But, in subsequent unloading or backward loading cycles, the bondslip behavior curve is constructed as along a line that joins the point of zero slip to the point of max negative slip. In this study, this approach is modified with Ko and Sato's study [22]. Ko and Sato [22] offer successful unloading stiffness-unloading slip formulations with $\mathrm{C}_{2}$ and $\mathrm{C}_{3}$ coefficients. They use linear approximations for bond-slip curves in order to find these coefficients and prove the efficiency of these formulas with their experimental results.

In this study, Harajli's approach is modified with Ko and Sato's investigation for subsequent cycles after first unloading/reloading cycle [21, 22]. For the first unloading/reloading cycle, Harajli's bond-slip model is applied just as the same and bond degradation ratio is taken as $78 \%$ same with authors' model. However, Harajli's approach is improved with Ko and Sato's formulations [22] and coefficients $C_{2}$ and $C_{3}$ are used for second and subsequent cycles. In Harajli's model [21], the unloading slope is determined according to first unloading in compression and stiffness degradation of bond behavior is assessed along the monotonic envelope curve of first unloading in subsequent cycles. This assumption was improved by degradation coefficients of Ko and Sato's model which updates to bond-slip curve in each cycle [22]. Because $\mathrm{C}_{2}$ and $\mathrm{C}_{3}$ directly construct a relationship between unloading stiffness and unloading slip values for the next portion after the first one, bond degradation ratio $\left(u_{\mathrm{n}} / u_{0}\right)$ is only taken into account in the first cycle. $\mathrm{C}_{2}$ and $\mathrm{C}_{3}$ are 0.5 and -1.9 consecutively same with the computations of Ko and Sato [22]. From the experimental results, $\mathrm{C}_{2}$ and $\mathrm{C}_{3}$ are developed empirically by Ko and Sato [22] considering the distinction between the backward stiffness and consecutive forward one. These coefficients are computed from the difference between maximum slip having the biggest value for this cycle and maximum slip in which bond-slip curve change its direction. This is also reflected to FEM calculations by frictional contact property in ABAQUS program v10 [27]. By this assessment, the unloading slope assumption along the monotonic envelope curve of Harajli [21] is developed and cyclic degradation of interface can be efficiently modeled for the next cycles. As a consequence to this improvement, much more realistic bond-slip behavior is attained and bond degradation is truly emphasized under cyclic loading. 


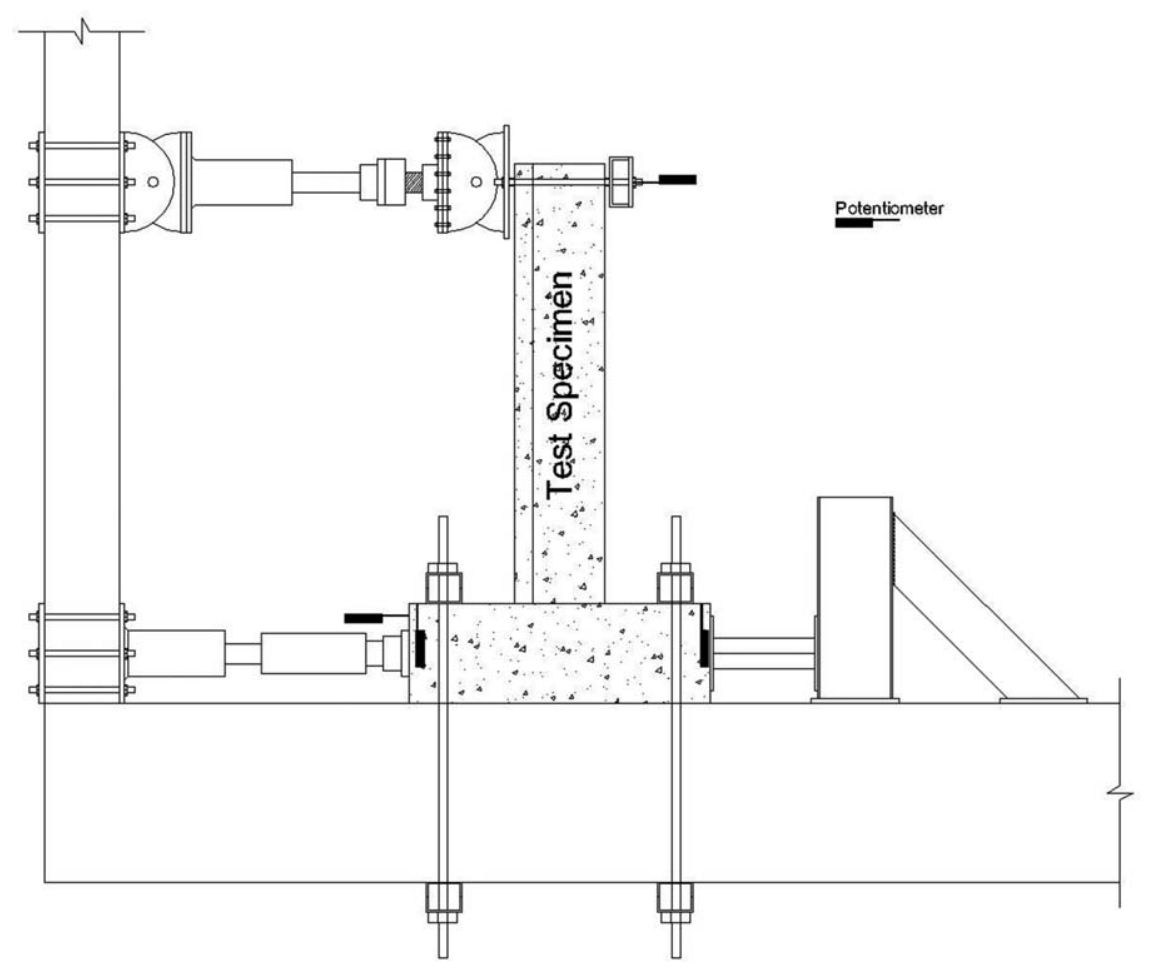

FIG. 2. A schematic view of experimental setup.

\section{EXPERIMENTAL}

All specimens were tested under cyclic loading. To this end, a loading column was designed with hinges at the free end of the beam. Loading column contains two hinges, a load cell and a hydraulic jack. Load was applied in cycles of loading and unloading. Load cycles were selected as they would help to evaluate the flexure and shear crack propagations. Loading was increased up to yield of flexural reinforcements or until the shear failure of the specimen. Four potentiometers were used to monitor displacements. The potentiometers were located at the end of the beam for the maximum displacement, under the rigid support to calculate the undesired displacement and finally on the rigid support to calculate the rotation. Eight strain gauges were used for each specimen. Strain gauges were attached at the section mid-height where shear cracks are expected to be developed, between 80 and $1600 \mathrm{~mm}$ apart from the beam's support. A schematic view of experimental setup and the arrangement of the measurement devices are shown in Fig. 2.

In this study, three-dimensional FE models were developed using the FE simulation code, ABAQUS v10 [27]. The results of these models were compared with the ones obtained from experimental tests and the validity of FEM results was made with reasonable accuracy. Figure 3 shows the dimensions and reinforcement details of the tested beam. The tested specimen was a T-beam connected to a rigid block. T-beam had 1,675 mm clear span, a total depth of $360 \mathrm{~mm}$, web width of $120 \mathrm{~mm}$, flange thickness of $75 \mathrm{~mm}$, and flange width of $360 \mathrm{~mm}$. The beam part of the model was reinforced with bottom and top three rebars, $20 \mathrm{~mm}$ in diameter at each level. Internal stirrups $6 \mathrm{~mm}$ in diameter were used with $300 \mathrm{~mm}$ spacing. In rigid block, the section was reinforced with bottom and top rebars $16 \mathrm{~mm}$ in diameter and internal stirrups were provided as $10 \mathrm{~mm}$ in diameter with $120 \mathrm{~mm}$ spacing. As shown in Fig. 4, the model was strengthened with 50-mm-wide CFRP strips. The clear spacing between CFRP strips was $60 \mathrm{~mm}$. The concrete class of the model was C30 and steel class was S420. The cyclic load was applied at $75 \mathrm{~mm}$ left from the beam's free end by a loading column. The cyclic load history is shown in Fig. 5.

Mechanical properties of concrete, steel, and CFRP strips are listed consecutively in Tables (1-3).

The adhesive, which is used at the interface between CFRP and concrete surface, has a modulus of elasticity of 4,500 $\mathrm{MPa}$, poisson ratio of $\eta=0.28$, and a tensile strength of $30 \mathrm{MPa}$. Elongation at failure is $0.009 \mathrm{~mm} /$ $\mathrm{mm}$. CFRP sheets were considered as orthotropic material and $3 \mathrm{D}$ modulus properties were used.

As stated earlier, the modeling and analysis of the beam model was carried out using the program ABAQUS v10 [23], which is seen also from Fig. 6. The concrete element was modeled using solid element with 3D stress mesh element type. For plastic behavior of concrete, concrete damaged plasticity option was chosen. This option led to proper definition of the failure mechanism of concrete elements. This represents completed inelastic 


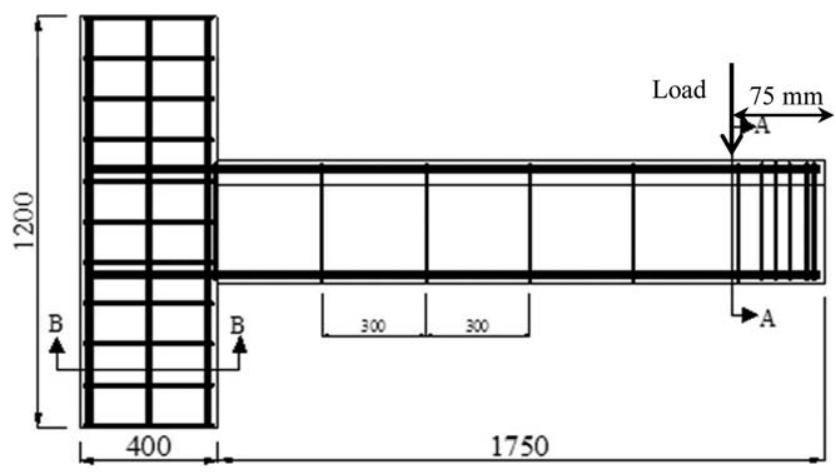

B-B

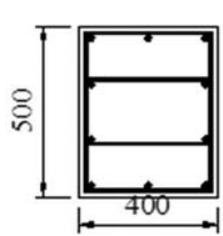

Column details

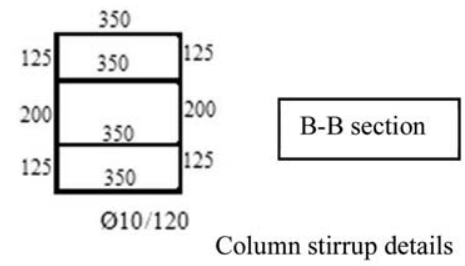

$\mathrm{T}$ beam details

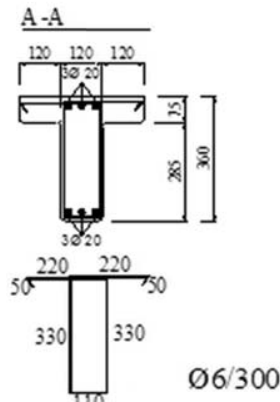

Beam stirrup details

A-A section

FIG. 3. Geometry and reinforcement details of the tested specimen
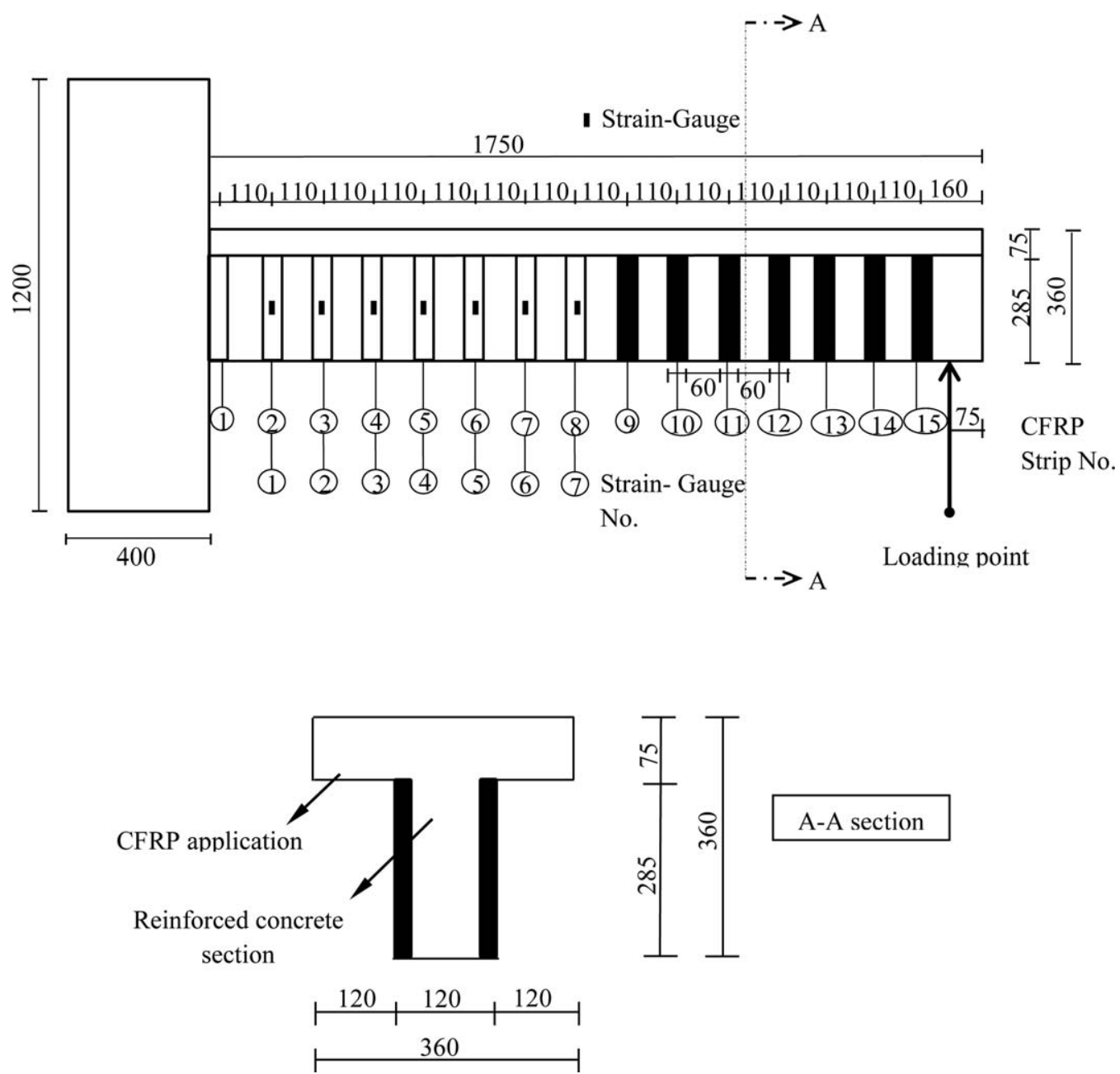

FIG. 4. CFRP configuration of tested specimen. 


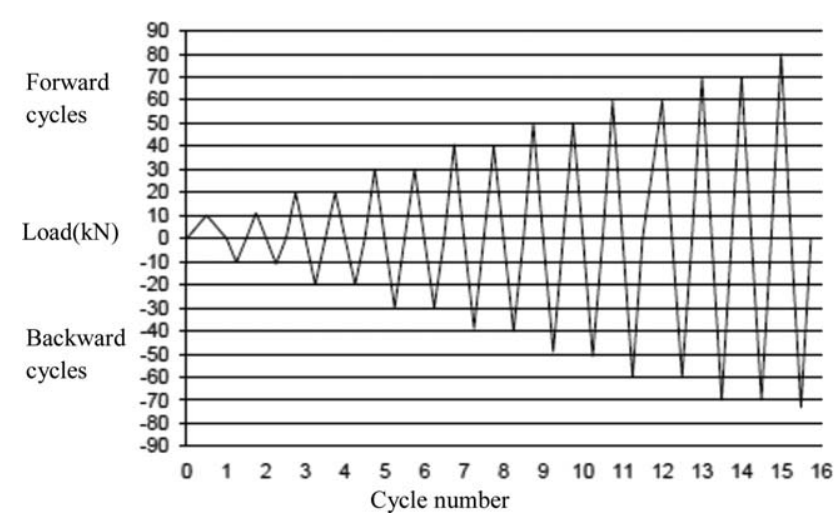

FIG. 5. Cyclic load history of the tested specimen.

behavior of concrete in both tension and compression including damage characteristics versus corresponding strain values. In the analysis undertaken, Modified ParkKent model [28] was used in post peak response of concrete, whereas tension stiffening was relied on Modified Bentz response stated in Ref. 29. The reinforcement steel bars were modeled using truss element with truss mesh element type. Elastoplastic option was employed with strain hardening in Seckin formulation [30] and stressstrain properties were given in Table 2 . The CFRP material model was considered as an orthotropic material that has its own coordinate and shell element was used with continuum shell mesh element type. In order to define mechanical properties of CFRP material, Hashin damage was introduced. By this way, four different failure modes were taken into account such as fiber tension, fiber compression, matrix tension, and matrix compression. The adhesive, epoxy resin element was modeled as shell element with continuum shell mesh element type. This layer was simulated as an isotropic elastic model. After that, it reached its ultimate tensile strength, failure became brittle, and the tensile strength decreased up to zero linearly at a strain of 0.012 .

In order to constrain steel reinforcement bars to concrete part, embedded option was employed. Perfect bond was considered for rebar-concrete interaction. For CFRPconcrete interaction, both two bond-slip relationships were taken into account as traction separation law. The

TABLE 1. Mechanical properties of concrete C30.

\section{Concrete}

Elastic modulus

Poisson ratio

Density

Dilatation angle

Initial plastic compression stress

Ultimate compression strength

Maximum tensile stress

Biaxial/uniaxial compression plastic strain ratio

Invariant stress ratio
TABLE 2. Mechanical properties of steel S420.

Steel

Elastic modulus

Poisson ratio

Density

Yield stress

Ultimate strength

$210,000 \mathrm{MPa}$

0.3

$7.8 \mathrm{t} / \mathrm{m}^{3}$

$365.217 \mathrm{MPa}$

$420 \mathrm{MPa}$

interface elements were formed as cohesive elements to simulate the debonding phenomena at the CFRP-concrete interface. They were placed at the top and bottom of the epoxy layer. Lu et al.'s [6] simplified bond-slip model was selected in order to compare the results of this study with obtained ones from Lu et al.'s technique. In spite of many bond-slip relationships proposed recently, $\mathrm{Lu}$ et al.'s technique explains accurately to bond-slip behavior constructing practically bilinear relationship in interface behavior. It provides a close agreement with experimental results under static loading. In conventional Lu et al.'s bond-slip modeling, the implemented interface elements were developed by the exponential form of $\mathrm{Xu}$ and Needleman [31] and Hawileh [32]'s studies. This developed cohesional zone was initiated by an increasing segment up to the ultimate shear stress $\tau_{\max }$ and its corresponding slip $\delta_{0}$. Ultimate shear stress $\tau_{\max }$ was equal to $3.3 \mathrm{MPa}$ and its corresponding slip $\delta_{0}$ was $0.045 \mathrm{~mm}$. The second part was constituted of softening response up to an ultimate slip value $\delta_{\mathrm{f}}$. The ultimate slip $\delta_{\mathrm{f}}$ was calculated as $0.18 \mathrm{~mm}$. The ultimate shear stress $\tau_{\max }$, its corresponding slip $\delta_{0}$, and the ultimate slip $\delta_{\mathrm{f}}$ were calculated according $\mathrm{Lu}$ et al.'s simplified technique. In this revised bond-slip model of this study, bond degradation ratio was adopted as $78 \%$ to bon-slip characteristics for first cycle and Ko and Sato [22] coefficients were added and updated to interface behavior in subsequent cycles.

TABLE 3. Mechanical properties of CFRP strips.

\section{CFRP}

Elastic modulus

E11

E22

E33

Poisson ratio

$\eta 12$

$\eta 13$

$\eta 23$

0.32

0.32

0.45

Shear modulus

G12

G13

G23

Longitudinal tensile failure stress

Longitudinal compressive failure stress

Transverse tensile failure stress

Transverse compressive failure stress

Longitudinal failure shear stress

4,500 MPa

4,500 MPa

$2,500 \mathrm{MPa}$

3,900 MPa

2,400 MPa

$111 \mathrm{MPa}$

$290 \mathrm{MPa}$

$120 \mathrm{MPa}$

Transverse failure shear stress 


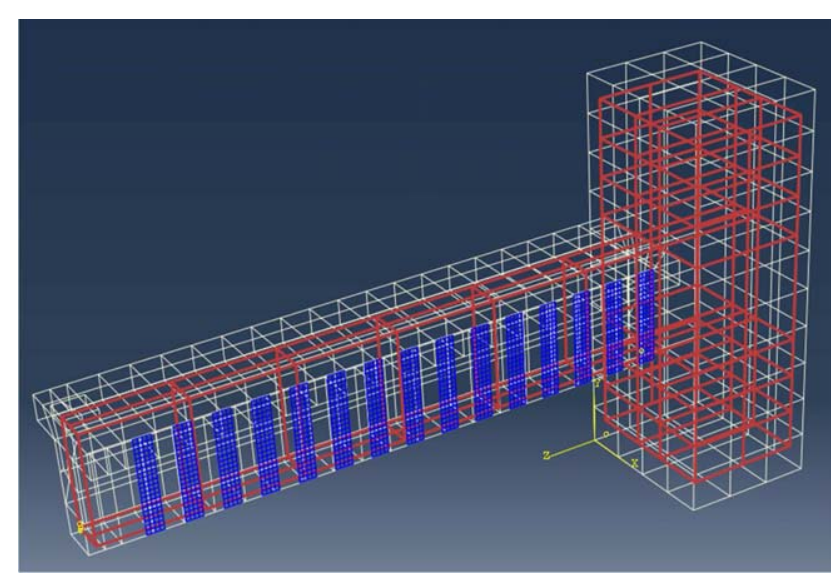

FIG. 6. Modeling studies on ABAQUS v10 [27] of structural system. [Color figure can be viewed at wileyonlinelibrary.com]

Ko and Sato [22] coefficients $\mathrm{C}_{2}$ and $\mathrm{C}_{3}$ were 0.5 and -1.9 , respectively. Ultimate shear stress $\tau_{\max }$ became equal to $2.98 \mathrm{MPa}$ and its corresponding slip $\delta_{0}$ was $0.0403 \mathrm{~mm}$. The ultimate slip $\delta_{\mathrm{f}}$ was obtained as $0.136 \mathrm{~mm}$.

Due to the complex nature of this structural system, convergence was hard to achieve with convergence tolerance limits. Thus, these limits were increased to be $10 \%$ for making it achievable according Newton-Raphson equilibrium iterations. As a result of this modification, convergence was successfully obtained at each cycle and any problems did not arise from equilibrium of forces and compatibility of displacement conditions.

\section{RESULTS AND DISCUSSION}

The experimental failure mechanism of this specimen was examined at each cycle in order to compare with the analytical results. Important events were noted for each cycle and the sequences of cracking, yielding, spalling, and failure modes were seen with high accuracy. First four cycles did not demonstrate any significant events since the mechanism was in the elastic stage. Flexural crack was first seen at $90 \mathrm{~mm}$ left from the joint at the back cycle of $30 \mathrm{kN}$ level. This was followed by other flexural cracks and two other flexural cracks occurred at the forward cycle of $40 \mathrm{kN}$ level. These two cracks were at 250 and $565 \mathrm{~mm}$ left from the joint and started to propagate to the sub surfaces of CFRP no 3 and no 6 strips. In the following back cycle of $40 \mathrm{kN}$, first flexural crack grew rapidly and crack width became $0.15 \mathrm{~mm}$. Next, new flexural cracks located at $855 \mathrm{~mm}$ left from the joint were seen in forward cycle of $50 \mathrm{kN}$ load level. Shear cracking was first observed at $420 \mathrm{~mm}$ left from the joint between CFRP no 4 and 5, followed by a drop of stiffness in both flexure and shear. Later, the shear strength of the specimen recovered to its previous values, but then started decreasing gradually with the opening of this shear crack in the forward cycle of 60 $\mathrm{kN}$. The sizes of flexural cracks were increased and first damage was observed as spalling of CFRP strip no 5 from concrete surface. This was followed by CFRP strip no 6 crush and second shear crack occurred at $620 \mathrm{~mm}$ left from the joint. Furthermore, first shear crack gradually propagated through the upper and lower beam and its width became $1 \mathrm{~mm}$. Second, significant damage occurred at back cycle of $70 \mathrm{kN}$ and CFRP strip no 4 is separated from concrete surface. It was reported that the shear cracks increased rapidly compared to the flexural cracks at the beam in the latter stages of loading. In forward cycle of 80 $\mathrm{kN}$, since first shear crack width grew extensively and became $5 \mathrm{~mm}$, load carrying capacity was at its maximum which is $79.88 \mathrm{kN}$ and corresponding displacement was $32.74 \mathrm{~mm}$ for loading point $\mathrm{B}$. The hysteretic response showed a pinched behavior indicating shear dominated fracture. So, the structural mechanism was observed as shear failure at back cycle of $80 \mathrm{kN}$ as that the specimen was failed in $73.01 \mathrm{kN}$ because of the first shear crack between CFRP no 4 and no 5 .

The load displacement behavior of specimen is shown in Fig. 7 for loading point B. While continuous line hysteresis loops demonstrate experimental results, dashed lines represent results of conventional bond-slip law (S1) and bond-slip law proposed (S2) in this study. In order to prevent from complexity, the last cycles of dashed line loops are given at ultimate level. As shown in Fig. 7, ultimate load value and corresponding displacement at point $\mathrm{B}$ are found as $79.88 \mathrm{kN} ; 32.74 \mathrm{~mm}$ in experimental study while $79.14 \mathrm{kN} ; 35.36 \mathrm{~mm}$ in the bond-slip law proposed and $84.81 \mathrm{kN} ; 46.68 \mathrm{~mm}$ in the conventional bond-slip law. An excellent agreement was reached between experimental and numerical analysis (S2) with bond slip developed in this study.

FE model with conventional $\mathrm{Lu}$ et al.'s bond-slip model (S1) predicted stiffness (tangent of curve) and

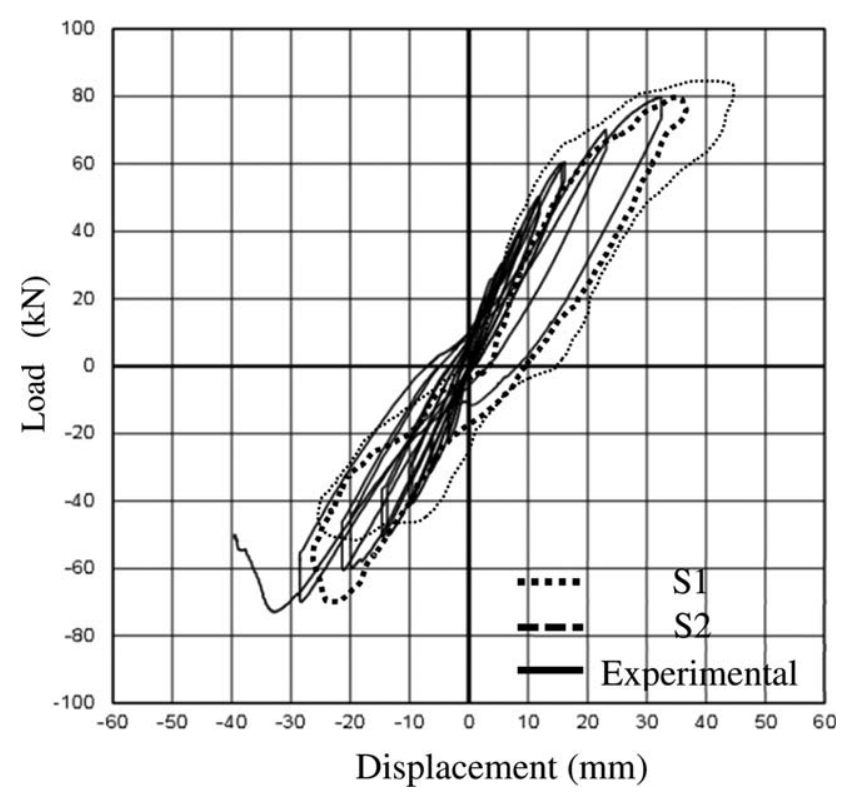

FIG. 7. Load-displacement response of models at loading point B. 


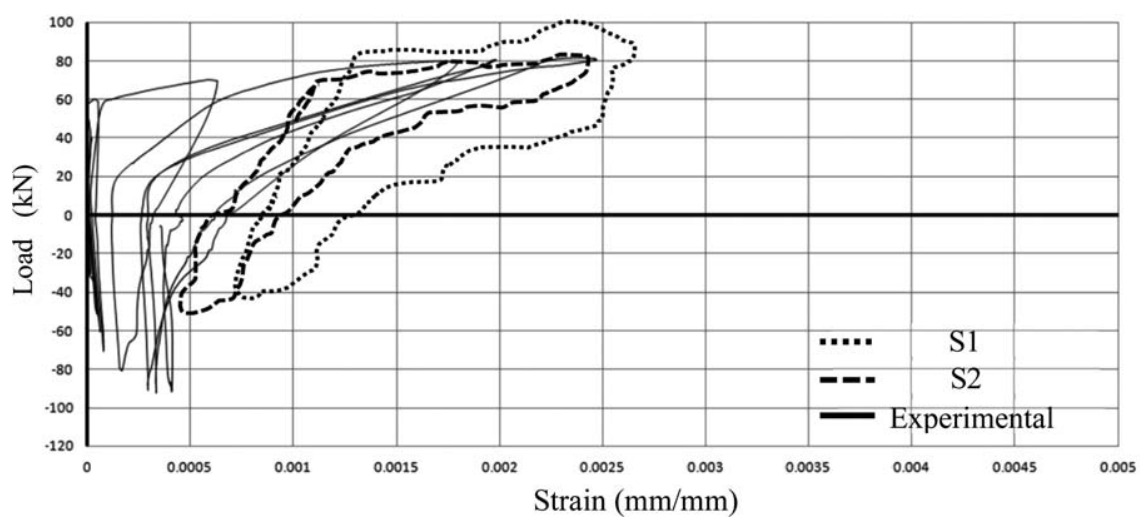

FIG. 8. Load-strain response of models at loading point B for CFRP no:9.

ultimate capacity values (load and displacement) higher than experimental and S2. This was because bond degradation due to the cyclic loading was not considered in S1. In other words, FRP-concrete interface cyclic bond deterioration was not adapted to models in S1. Similarly, the energy capacity of specimen which is the area enclosed by load-displacement relationship was determined closer to experimental work with $\mathrm{S} 2$, whereas it was overestimated with S1 (no cyclic degradation). S1 showed more ductile behavior since cyclic mechanism was omitted. As the cyclic load increased, the slope of each loading/ reloading path gradually decreased which is seen also from experimental results and it is proved that the stiffness decrease was such an important parameter that should not be ignored.

CFRP no 5, no 9, and no 15 strain responses were examined under loading since they had maximum and minimum strain values. Load-strain responses of CFRP no 9 and no 15 were proposed in Figs. 8 and 9, consecutively. A close agreement was also seen from Figs. 8-10 and in CFRP no 9, the max strain was 0.00242 for $\mathrm{S} 2$, 0.0026 for $\mathrm{S} 1$, and 0.00245 for experimental study. In CFRP no 5, the max strain decreased to 0.00091 for $\mathrm{S} 2$, 0.0011 for $\mathrm{S} 1$, and 0.00087 for experimental study. In CFRP no 15, the max strain took the smallest values among these three ones and became 0.000076 for S2, 0.000075 for $\mathrm{S} 1$, and 0.000066 for experimental study.

While S1 strain values of CFRP were overestimated for no 5 and no 9, S2 gave successful results for all three sheets (no 5, 9, and 15). S1 predicted more ductile response than existed in experimental result, in terms of strain values due to the omission of bond deterioration. For CFRP no 5 and 9, cycle of fine-dashed loops was further away from large-dashed loop and load-strain behavior differed particularly in positive direction. In CFRP no 15 , even though a close agreement was reached in ultimate strain capacity value, load values were predicted to be lower than the other techniques. However, it should also be noted that the maximum load difference in negative direction existed in CFRP no 5 and no 15. The drops in the load were sharp between positive and negative directions. As shown also from S2 models, FRP strain values varied between 0.1 and $0.3 \%$. When shear crack width became $5 \mathrm{~mm}$ and peak load level was $79.9 \mathrm{kN}$, max FRP strain is obtained as $0.22 \%$. At this point, it can be said that cyclic FRP-concrete bond degradation decreased the strain capacity of FRP strain and FRP no 9 reached ultimate capacity in $0.22 \%$ strain value even though the effective strain value has been proposed as $0.6 \%$ for FRPs in Federation International du Beton-

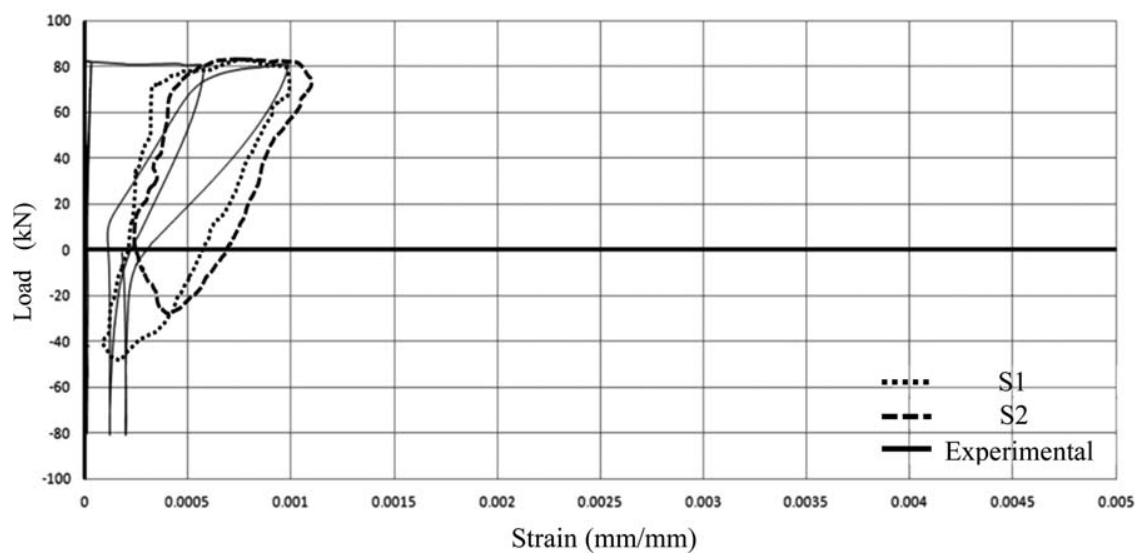

FIG. 9. Load-strain response of models at loading point B for CFRP no: 5. 


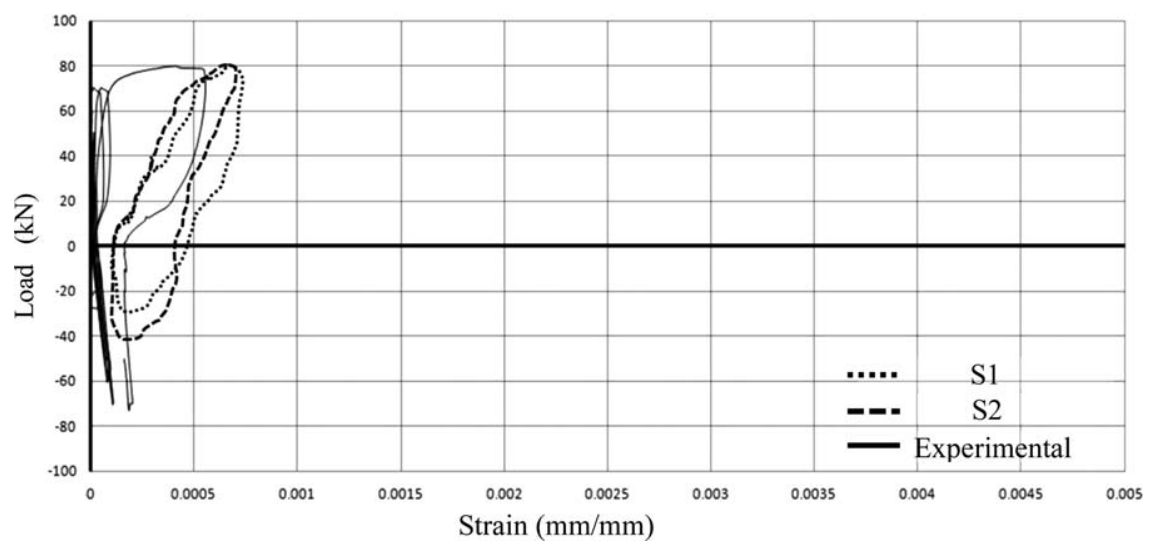

FIG. 10. Load-strain response of models at loading point B for CFRP no:15.

Eurocode 2 (FIB) [33-35]. If a displacement-based design would be carried out, FRP strains between 0.25 and $0.35 \%$ can be considered. However, this range is far from proposed one in FIB [33-35]. This value should be updated under cyclic load stiffness deterioration taking into account CFRP-concrete interface behavior.

At $60 \mathrm{kN}$ level, the reduction in shear capacity of concrete was proved by occurrence of first crack formation. With shear crack formation and reduction of aggregate interlock, in the second forward cycle of $60 \mathrm{kN}$, crack size was widened and became crucial for neighbor FRP strips.
Because the reduction in shear capacity of wrapped FRPs is governed by gradual stress accumulations under cyclic loading and spalling or fracture of FRP strips around the shear cracks. Max strain values were obtained in CFRP no 9 since it was much closer to shear crack formation than the other strips. Development of cracking was continued even if in backward cycles under cyclic degradation. It is worth noting that FRP strain increase was much higher than the linear bond-slip portion when CFRP-concrete interface reached to slip value $(6 \mathrm{~mm})$ corresponding to max shear bond stress. After exceeding this slip value of

TABLE 4. Longitudinal strain values of concrete layers under CFRP strips (no 5, 9, and 15) from experimental, conventional bond slip (S1), and bond slip proposed (S2) in this study.

\begin{tabular}{|c|c|c|c|c|c|c|c|c|c|}
\hline \multirow[b]{3}{*}{ Load level $(\mathrm{kN})$} & \multicolumn{9}{|c|}{ Longitudinal strain(mm/mm) } \\
\hline & \multicolumn{3}{|c|}{ CFRP no. 5} & \multicolumn{3}{|c|}{ CFRP no. 9} & \multicolumn{3}{|c|}{ CFRP no. 15} \\
\hline & Exp. & S1 & $\mathrm{S} 2$ & Exp. & $\mathrm{S} 1$ & S2 & Exp. & S1 & S2 \\
\hline 10 & $5 E-5$ & $4 E-5$ & $4 E-5$ & $5 \mathrm{E}-5$ & $5 \mathrm{E}-5$ & $5 \mathrm{E}-5$ & $3 E-5$ & $4 \mathrm{E}-5$ & $3 E-5$ \\
\hline 30 & $1.2 \mathrm{E}-4$ & $1.2 \mathrm{E}-4$ & $1.2 \mathrm{E}-4$ & $8 \mathrm{E}-5$ & $9 E-5$ & $9 \mathrm{E}-5$ & $4 E-5$ & $4.49 \mathrm{E}-5$ & $4.5 \mathrm{E}-5$ \\
\hline 50 & $1.3 \mathrm{E}-4$ & $1.3 \mathrm{E}-4$ & $1.3 \mathrm{E}-4$ & $9 E-5$ & $9.6 \mathrm{E}-5$ & $1 \mathrm{E}-4$ & $5 E-5$ & $5 \mathrm{E}-5$ & $5 E-5$ \\
\hline 60 & $2.1 \mathrm{E}-4$ & $2.1 \mathrm{E}-4$ & $2.2 \mathrm{E}-4$ & $1.4 \mathrm{E}-4$ & $1.1 \mathrm{E}-4$ & $1.1 \mathrm{E}-4$ & $7 \mathrm{E}-5$ & $6 \mathrm{E}-5$ & $7 E-5$ \\
\hline 79.8 (max load) & $4.5 \mathrm{E}-4$ & $4.1 \mathrm{E}-4$ & $4.2 \mathrm{E}-4$ & $2.8 \mathrm{E}-4$ & $2.6 \mathrm{E}-4$ & $2.8 \mathrm{E}-4$ & $9 E-5$ & $9 E-5$ & $9 \mathrm{E}-5$ \\
\hline
\end{tabular}

TABLE 5. Longitudinal strain values of concrete layers under CFRP strips (no 5, 9, and 15) from experimental, conventional bond slip (S1), and bond slip proposed (S2) in this study as shown by errors according to experimental results.

Longitudinal strain $(\mathrm{mm} / \mathrm{mm})$

\begin{tabular}{|c|c|c|c|c|c|c|c|c|c|}
\hline \multirow[b]{2}{*}{ Load level $(\mathrm{kN})$} & \multicolumn{3}{|c|}{ CFRP no. 5} & \multicolumn{3}{|c|}{ CFRP no. 9} & \multicolumn{3}{|c|}{ CFRP no. 15} \\
\hline & Exp. & $\mathrm{S} 1$ error & S2 error & Exp. & S1 error & $\mathrm{S} 2$ error & Exp. & S1 error & S2 error \\
\hline 10 & $5 \mathrm{E}-5$ & -0.2 & -0.2 & $5 E-5$ & 0 & 0 & $3 E-5$ & 0.333 & 0 \\
\hline 30 & $1.2 \mathrm{E}-4$ & 0 & 0 & $8 E-5$ & 0.125 & 0.125 & $4 E-5$ & 0.1225 & 0.125 \\
\hline 50 & $1.3 E-4$ & 0 & 0 & $9 E-5$ & 0.0666 & 0.111 & $5 E-5$ & 0 & 0 \\
\hline 60 & $2.1 \mathrm{E}-4$ & 0 & 0.047 & $1.4 \mathrm{E}-4$ & -0.214 & -0.214 & $7 \mathrm{E}-5$ & -0.143 & 0 \\
\hline 79.8 (max load) & $4.5 \mathrm{E}-4$ & -0.0888 & -0.0666 & $2.8 \mathrm{E}-4$ & -0.0714 & 0 & $9 E-5$ & 0 & 0 \\
\hline
\end{tabular}


concrete-CFRP bond interface, FRP strain increase was governed by bond degradation ratio $\left(u_{n} / u_{0}\right)$ and was obtained as max value in max slip. Thus, the most important parameters were slip value corresponding to max shear bond stress and bond degradation ratio $\left(u_{\mathrm{n}} / u_{0}\right)$.

Similarly, as seen from Table 4 , concrete strain values in S1 were slightly higher than experimental and S2. While CFRP-concrete interface bond values were ranging from max shear point to max slip value, concrete longitudinal strain increased very slowly and did not reach to higher values. Table 5 proves absolutely the agreement between experimental and proposed model results by help of errors according to the experimental results. At this point, it can be said that cyclic bond degradation affected interface behavior and it provided that the max bond shear stress was obtained as being lower than no cyclic deterioration case (S1) in higher slip values and when bond reached to shear capacity, concrete longitudinal strain values were supposed to increase significantly. It should be emphasized that the concrete longitudinal strain values tended to increase higher after CFRP-concrete interface shear bond capacity exceeded. This is an important point which showed us that cyclic bond deterioration has to be considered in effective modeling strategies.

\section{CONCLUSIONS}

This study was conducted in order to propose an effective CFRP-concrete interface bond-slip model under cyclic loading. It was aimed to develop realistic CFRPconcrete interface bond-slip relationship which can add cyclic degradation to structural response evaluations in CFRP retrofitting RC systems. For this, Harajli's model [21] was further developed with Ko and Sato's model [22]. An excellent agreement was reached between experimental results and bond-slip relationship of this study. The response difference between results of Lu's exponential model [6] and this revised interface relationship of this study demonstrated that the omission of cyclic deterioration to CFRP-concrete bond-slip behavior can lead to inaccurate and unreliable assessments when evaluating structural performance under cyclic loading. Both experimental and analytical studies pointed out that bond-slip law for CFRP to concrete interface should be considered for cyclic degradation and updated according to the stiffness decreases consequently. Thus, in CFRP retrofitted RC systems subjected to cyclic loading, limitations of strength, strain, and ductility parameters stated in codes should be updated taking into consideration of cyclic deterioration on CFRP-concrete bond-slip behavior. For example, with the bond slip proposed in this study, max FRP strain was obtained as $0.22 \%$ in failing point of system due to shear crack formation, even though the effective strain value has been proposed as $0.6 \%$ for FRPs in FIB [33-35]. These structural response and result differences between cyclic and no cyclic bond-slip behaviors strongly emphasize that more analytical verifications stud- ies should be undertaken to further tests and further work is required in the studies based on cyclic deterioration on CFRP-concrete interface bond, particularly in terms of displacement and slip capacity of subsequent cycles after the first one.

\section{REFERENCES}

1. T. Ueda and J.G. Dai, New shear bond model for FRPconcrete interface - from modelling to application. FRP composites in civil engineering - CICE 2004, Adelaide, Australia, 69 (December 2004).

2. J.G. Dai and T. Ueda, Local bond stress slip relations for FRP sheets concrete interfaces. In: Proc. of 6th International Symposium on FRP Reinforcement for Concrete Structures, Singapore, World Scientific Publications, 143 (2003)

3. X.Z. Lu, J.J. Jiang, J.G. Teng, and L.P. Ye, Constr. Build. Mater., 20(6), 412 (2006).

4. X.Z. Lu, L.P. Ye, J.G. Teng, and J.J. Jiang, Eng. Struct., 27(4), 564 (2005).

5. K. Nakaba, K. Toshiyuki, F. Tomoki, and Y. Hiroyuki, ACI Struct. J., 98(3), 359 (2001).

6. X.Z. Lu, J.G. Teng, and L.P. Ye, Eng. Struct., 27, 920 (2005).

7. T. Ueda, J.G. Dai, and Y. Sato, A nonlinear bond stressslip relationship for FRP sheet-concrete interface. In: Proc. of International Symposium on Latest Achievement of Technology and Research on Retrofitting Concrete Structures, 113 (2003).

8. J.F. Chen and W.K. Pan, Constr. Build. Mater., 20(1-2), 46 (2006).

9. Y.F. Wu, .Z.Y. Wang, K. Liu, and W. He, Comput.-Aided Civil Infrastruct. Eng. (CACAIE), 24(5), 371 (2009).

10. B. Ferracuti, M. Savoia, and C. Mazzotti, Compos. Struct., 80(4), 523 (2007).

11. C. Mazzotti, M. Savoia, and B. Ferracuti, Constr. Build. Mater., 22(7), 1409 (2008).

12. P. Cornetti and A. Carpinteri, Eng. Struct., 33, 1988 (2011).

13. H. Yuan, X. Lu, D. Hui, and L. Feo, Compos. Struct., 94(12), 3781 (2012).

14. K .Liu and Y.F. Wu, Compos. B, 43, 1955 (2012).

15. Y.W. Zhou, Y.F. Wu, and Y. Yun, Compos. B, 41, 423 (2010).

16. H. Abdel Baky, U.A. Ebead, and K.W. Neale, Eng. Struct., 39, 11 (2012).

17. H. Neubauer and U. Rostasy, Bond failure of concrete fiber reinforced polymer plates at inclined cracks - experiments and fracture mechanics model, Proc. of 4th International Symposium on Fiber Reinforced Polymer Reinforcement for Reinforced Concrete Structures, SP-188, Americal Concrete Institute, Farmington Hills (MI), USA, 369 (1999).

18. H.C. Biscaia, C. Chastre, and M.A.G. Silva, Compos.: Part $B, 45,1554$ (2013).

19. M. Savoia, B. Ferracuti, and M. Mazzotti, Non linear bondslip law for FRP-concrete interface, Proc. of 6th International Symposium on FRP Reinforcement for Concrete 
Structures, FRPRCS-6, World Scientific Publications, Singapore, 163 (2003).

20. G. Monti, M. Renzelli, and P. Luciani, FRP adhesion in uncracked and cracked concrete zones, Proc. of 6th International Symposium on FRP Reinforcement for Concrete Structures, FRPRCS-6, World Scientific Publications, Singapore, 183 (2003).

21. M.H. Harajli, J. Struct. Eng., 135(5), 509 (2009).

22. H. Ko and Y. Sato, J. Compos. Constr., 11(4), 419 (2007).

23. J. Pan and Y.F. Wu, Compos. Part: B, 61, 17 (2014).

24. G. Fabbrocino, G.M. Verderame, G. Manfredi, and C. Edoardo, Eng. Struct. 26(4), 2137 (2004).

25. M. Favvata, B. Izzuddin, and C. Karayannis, Earthquake Eng. Struct. Dyn., 37(13), 1527 (2008).

26. Comite Euro International du Beton, Rc Elements Under Cyclic Loading: State of the Art Report, Thomas Telford (1996).

27. ABAQUS version 12.4 User Manual, Hibbitt, Karlsson and Sorensen Incorporation, Powtucket, Rhode Island (2013).
28. R. Park, J. Earthquake Eng., 6(2), 147 (2002).

29. E.C. Bentz, S. Buckley, and R. Gettu, ACI Struct. J., 103 (5), 757 (2006).

30. M. Seçkin, Hysteretic behavior of cast-in-place exterior beam-column-slab assemblies, Ph.D. Thesis, Department of Civil Engineering, University of Toronto, Toronto (1981).

31. X.-P. Xu and A. Needleman, J. Mech. Phys. Solids, 42, 1397 (1994).

32. R. Hawileh, Constr. Build. Mater., 27, 461 (2012).

33. FIB, Seismic assessment and retrofit of reinforced concrete buildings: State-of-the-art report, International Federation for Structural Concrete (fib), Lausanne, Switzerland (2003).

34. EN 1992-1-1. Eurocode 2: Design of concrete structures part 1-1: general rules for building and civil engineering structures. European Committee for Standardization (2005).

35. EN 1998-1. Eurocode 8: Design of structure for earthquake resistance - Part 1: General rules seismic actions and rules for buildings. European Committee for Standardization (2005). 